\title{
DERMATOPHYTOSIS CAUSED BY Trichophyton verrucosum IN A THREE MONTH OLD CALF IN SHENDAM, PLATEAU STATE, NIGERIA
}

\section{DALIS J.S. ${ }^{*}$, KAZEEM H.M. ${ }^{2}$, KWAGA J.K.P. ${ }^{3}$, KWANASHIE C.N. ${ }^{2}$, MUHAMMED M. ${ }^{1}$, OKEWOLE P.A. ${ }^{1}$, SHAMAKI D. ${ }^{1}$ AND AHMED M.S. ${ }^{1}$}

${ }^{1}$ National Veterinary Research Institute, Vom, Nigeria.

2Department of Veterinary Microbiology, Faculty of Veterinary Medicine, Ahmadu Bello University, Zaria, Nigeria.

3Department of Veterinary Public Health and Preventive Medicine, Faculty of Veterinary Medicine, Ahmadu Bello University Zaria, Nigeria.

*Corresponding Author: Email- dalisjames280@yahoo.com

Received: March 02, 2014; Accepted: May 15, 2014

\begin{abstract}
A three-month-old calf was seen to have skin lesions involving the head and neck especially around the eyes. The lesions were circular, circumscribed, crusty, grayish-white and perceptibly raised above the skin. Skin scrapings and hair pullouts were aseptically collected and processed for mycology. Direct examination of hair in $20 \% \mathrm{KOH}$ showed chains of ectothrix spores. Microscopic examination of the isolate stained with lactophenol cotton blue revealed septate hyphae with numerous clavate microconidia borne laterally from the hyphae and a single longish, thick, smooth- walled, and multi-septated macroconidia with characteristic rat tail (string bean shaped) suggestive of $T$. verrucosum. There was no growth on casein vitamin free agar but good growth was observed on medium containing thiamine and inositol. Information on bovine dermatophytosis from Nigeria is scanty.

This finding is significant as it indicates that bovine dermatophytosis may be present in an economically important proportion among cattle especially young animals in Nigeria. The need to carry out more studies on the disease among the cattle population in the country with a view to instituting prevention and control measures was emphasized.
\end{abstract}

Keywords- Dermatophytosis, Trichophyton verrucosum, calf, Shendam, Plateau state, Nigeria

Citation: Dalis J.S., et al. (2014) Dermatophytosis Caused by Trichophyton verrucosum in a Three Month Old Calf in Shendam, Plateau State, Nigeria. International Journal of Microbiology Research, ISSN: 0975-5276 \& E-ISSN: 0975-9174, Volume 6, Issue 1, pp.-515-518.

Copyright: Copyright@2014 Dalis J.S., et al. This is an open-access article distributed under the terms of the Creative Commons Attribution License, which permits unrestricted use, distribution and reproduction in any medium, provided the original author and source are credited.

\section{Introduction}

Dermatophytosis (ringworm) is a superficial infection of the keratinacious epidermidermal layers of the skin, hair and nails caused by dermatophytes (Microsporum, Trichophyton and Epidermophyton). The Genus Epidermophyton has only one pathogenic species ( $E$. floccosum) causing disease only in human beings while Microsporum and Trichophyton are complex and comprise of multiple species that are pathogenic to both man and animals [1,2]. Dermatophytes have been classified based on their natural habitat as geophilic, zoophilic or anthropophilic [1]. Ringworm fungi are found all over the world but grow best in warm and humid environments and are therefore, more common in tropical and subtropical regions where they cause considerable losses as a result of decreased production, public health concern, premature culling, treatment costs and downgrading of hides and skin [3- 5].

Ringworm is zoonotic and highly contagious. Once the disease is introduced into a herd, it spreads rapidly among susceptible animals. Close confinement, age, breed of animal and production system coupled with prolonged wetting are believed to be important predisposing factors $[5,6]$. The typical lesion in cattle is a heavy, grey-white crust, circular and raised above the skin most frequently found on the head and neck, especially around the eyes and face, but may, in severe cases, be found all over the body $[7,8]$. It had been observed that the greatest economic and human health problems in the developed countries come from dermatophytosis of domestic cats and cattle. Approximately $60 \%$ of children were affected by tinea capitis in some regions, and more than $50 \%$ of the population in some parts of Europe was reported to have tinea pedis [9]. Ringworm in humans is usually characterized by pruritus and inflammation that is most severe at the edges, with erythema, scaling and occasionally blister formation. Central clearing is sometimes seen, particularly in tinea corporis resulting in the formation of a classic "ringworm" lesion [9]. In spite of the significance of ringworm in global economy, the disease has not been adequately studied in Nigeria. Although some attempts have been made at documenting human dermatophytosis in the country $[4,10,11]$, information on ringworm of animals are scanty and rarely reported [12].

This paper presents a report of dermatophytosis due to $T$. verrucosum in a three-month old calf in Shendam, Plateau State, Nigeria.

\section{Materials and methods}

A three- month- old calf having alopecic, circular, circumscribed, crusty, grayish-white, raised, skin lesion involving mostly the head 
and neck especially around the eyes was examined. This calf was in the same herd with ten other cattle aged between 2 to 5 years but only the calf showed visible skin lesions. Three of the adult animals had at different times developed a similar lesion when they were about the same age with the calf in this study and were treated with local herbs. Skin scrapings were collected at the edge of the lesions together with some hair pull outs after cleaning with cotton wool soaked in $70 \%$ alcohol and sent to the Mycology Laboratory, National Veterinary Research Institute, Vom for laboratory diagnosis.

\section{Laboratory Examination}

The sample was divided into two portions. One part was used for direct microscopic examination and the remaining part was used for fungal isolation by culture.

\section{Direct Microscopic Examination}

The hair sample was placed on a clean glass slide containing a drop of $20 \%$ potassium hydroxide solution and covered with a cover slip. The slide was gently heated over a flame from a Bunsen burner and examined for the presence of spores and hyphae under a light microscope following the standard laboratory procedures.

\section{Fungal Culture, Isolation and Identification}

The portion for fungal isolation was seeded onto Dermasel agar (OXOID) containing: Mycological peptone, $10.0 \mathrm{~g} / \mathrm{L}$; Glucose, 20.0g/L; Agar, 14.5g/L; Cyclohexamide, $0.4 \mathrm{~g} / \mathrm{L}$ and Chloramphenicol, $0.05 \mathrm{~g} / \mathrm{L}, \mathrm{pH} 6.9$, incubated at $37^{\circ} \mathrm{C}$ for $2-6$ weeks and examined for fungal growth. Suspicious colonies were sub- cultured onto fresh Dermasel agar and incubated at $37^{\circ} \mathrm{C}$ for 21 days. Identification of fungal growth was carried out by both macroscopic and microscopic examination which included growth rate, general topography, surface and reverse pigmentation. Microscopic identification of positive fungal cultures was carried out using the method described by koneman [13]. A drop of lactophenol cotton blue stain was placed on a clean glass slide. A portion of mycelium was transferred onto the lactophenol cotton blue stain and teased with a 22 gauge nichrome needle to separate the filaments. Cover slip was placed on the preparation and examined under low and high power magnification for microscopic fungal structures.

\section{Nutritional Requirements}

The organism was inoculated onto casein vitamin free-agar (T1 agar), T1+inostol (T2), T1+inositol+thiamine (T3), T1+thiamine (T4) and incubated at room temperature for 14 days.

\section{Results}

Alopecic, circular circumscribed, crusty, grayish-white, raised skin lesions were seen on the head and neck particularly around the eyes [Fig-1]. Chains of large ectothrix spores were observed on infected hair by direct examination. Colonies on SDA were white, cottony, heaped, raised and slightly folded [Fig-2]. Microscopic examination of isolates stained with lactophenol cotton blue revealed septate hyphae with numerous clavate microconidia borne laterally from the hyphae some of which were breaking into arthrospores [Fig-3]. A single longish, thick, smooth- walled and multi-septated macroconidia with characteristic rat tail (string bean shaped) typical of $T$. verrucosum [Fig-4]. There was no growth on T1and T4, minimal submerged growth on T2 while good growth was observed on T3 [Fig-5].

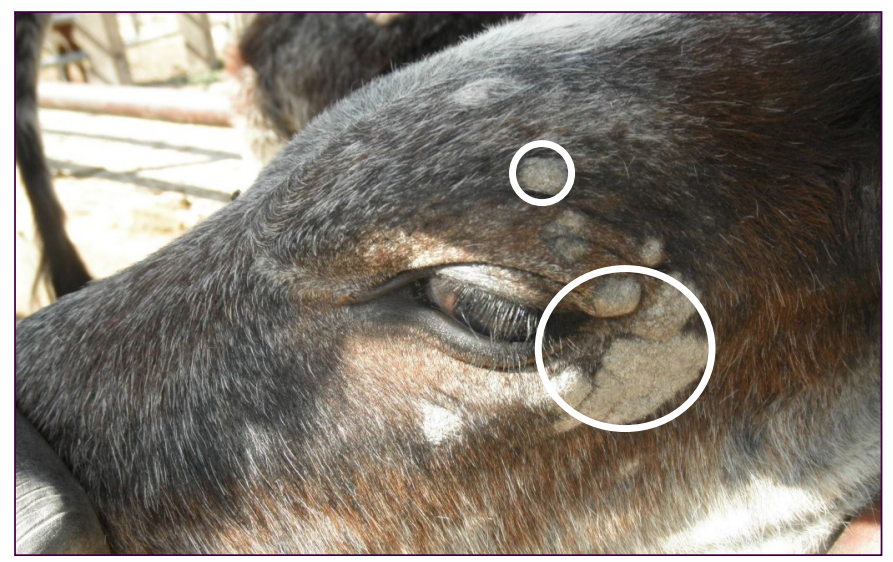

Fig. 1- Head of a 3 months old calf with thick, crusty, grayish- white raised lesions around the eyes (Circled).

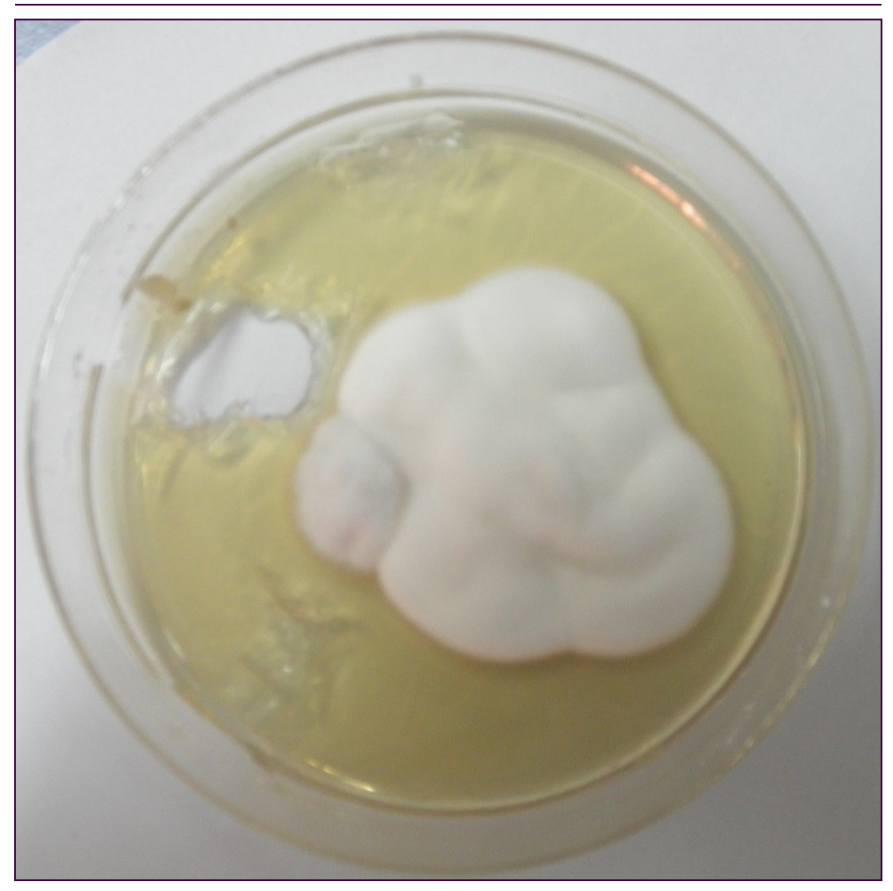

Fig. 2- Culture of $T$. verrucosum on SDA with white, cottony, heaped and slightly folded surface growth.

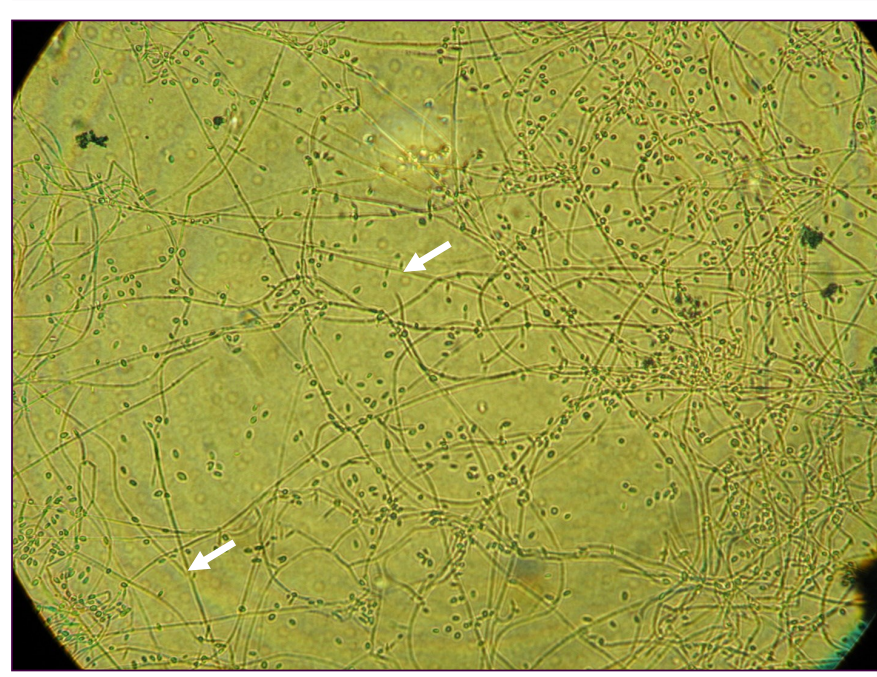

Fig. 3- Microscopic morphology of $T$. verrucosum. Note small calvate microconidia laterally attached to the hyphae (arrow). 


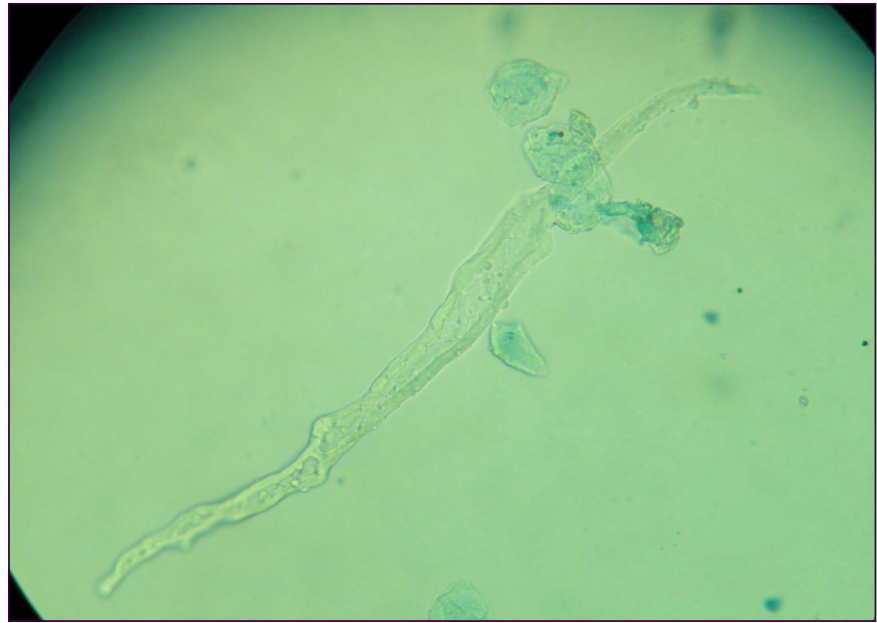

Fig. 4- Characteristic rat tail or string bean-shaped macroconidia of T. verrucosum

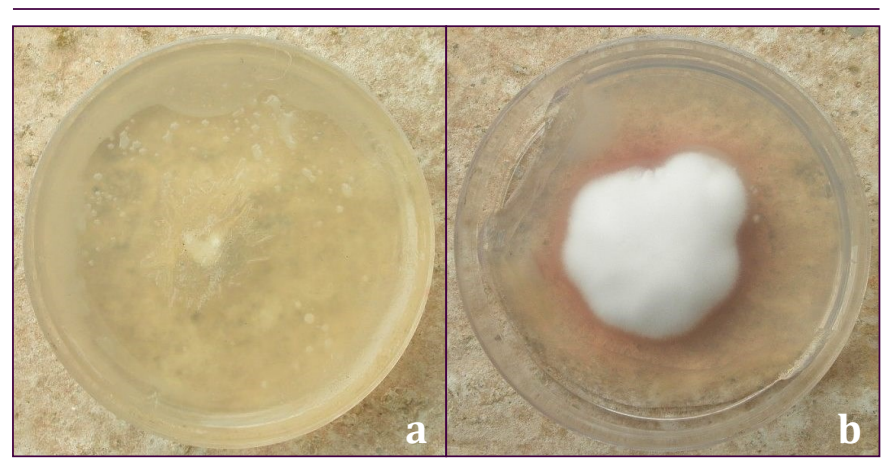

Fig. 5- Growth on T1vitamin free verses T3 with inositol (a) and thiamine (b)

\section{Discussion}

Trichophyton verrucosum was the cause of ringworm in a threemonth-old calf in Shendam, Plateau State, Nigeria. Our finding is significant as it indicates that bovine dermatophytosis may be present in an economically important proportion among cattle especially young animals in this country. This report is consistent with previous findings $[8,14,15]$ that calves have higher risk of being infected by dermatophytes than adult cattle. This could be attributed to the poorly developed immune system in the young animals. The warm and humid climatic condition might have predisposed the animal to infection [3,14].

The diagnosis of ringworm in this study was based on clinical signs, direct examination and isolation of causal agent from culture. As in previous studies $[7,8]$ the main lesions of ringworm seen in this report were alopecic, circular circumscribed, crusty, grayish-white, raised skin lesions, seen on the neck and head region especially around the eyes of the animal. However, the clinical manifestation of ringworm in cattle is not always typical and can sometimes be confused with other skin diseases such as dermatophilosis and mange [14]. This makes the importance of laboratory examination for confirmation of diagnosis quite obvious. The presence of ectothrix spores on hair surfaces by direct examination in this report agrees with those in the literature [16-18]. Direct examination is essential, as it allows the clinician to start treatment pending culture. Although, it is a highly efficient screening technique [19], nevertheless, it is limited because a fungus cannot be identified to species level by this method. Culture is therefore, a valuable and often obligate complement to direct examination. Isolation of the pathogen by culture and its identification at species level are important since prophylaxis and therapy may vary depending on species [18].

According to Rosen [16], T. verrucosum should be considered if a colony is slow growing and white, with a smooth folded surface. Colonies of $T$. verrucosum in this report were slow growing, white, cottony, heaped, smooth and slightly folded with some submerged growth and yellow reverse pigment. This observation is consistent with the findings of AL-Ani, et al [7], Rosen [16] and Forbes, et al [17]. It however, differs from the report of Shams-Gahfarokhi, et al [20] who described the growth of $T$. verrucosum on selective agar for pathogenic fungi medium as small, button-like, white-cream colored, with suede-like to velvety surface, a raised centre and flat periphery with some submerged growth. This difference could be as a result variation in the strains studied. Microscopically, septate hyphae with numerous clavate microconidia borne laterally from the hyphae, with a single longish, thick and smooth- walled, multiseptated macroconidia with characteristic rat tail (string bean shaped) typical of $T$. verrucosum. This is consistent with the findings of Kane \& Smitka [21] who reported the production of macroconidia in 8 out of 35 isolates of $T$, verrucosum when they grew the organisms on Bromocresol purple casein yeast extract agar. Not all species of $T$. verrucosum produce conidia [16]. However, many researchers have reported the microconidia producing strain $[15,17,21]$. Nevertheless, the presence of typical macro conidia had been described as diagnostic [15].

The absence of growth on casein vitamin free agar coupled with good fungal growth on medium containing thiamine and inositol, confirmed the report of Weitzman, et al [22] Who observed enhanced growth of $T$. verrucosum on Trichophyton 2 and 3 agars.

$T$. verrucosum has been documented as the most common cause of ringworm in cattle, sheep and goats $[7,8,23]$ and has been isolated from different animals in many parts of the world : from cattle in Iran [20,24], China [25], Australia [26], from Camels and a goat in Sudan $[27,28]$ and recently from a horse in Nigeria [29].

Animals are the major reservoirs of zoophilic dermatophytes. $T$. verrucosum is able to survive in skin lesions of the infected animals for several months. In most animals, symptoms of mycoses are recognized too late and are often left untreated, leading to transfer of infections to humans [24]. Human dermatophytosis caused by $T$. verrucosum resulting from close contact with cattle has been reported $[4,10,11,30]$.

Apart from human involvement, cattle ringworm causes serious economic effects on affected farms due to decrease in meat and milk production, reduced growth rate and poor quality hides due to skin damage [5]

Treatment of bovine ringworm is expensive, time consuming and often failed. Wabacha, et al [3] found out that lesions of trichophytosis persisted during more than 17 weeks and most of the calves did not respond to topical treatment with various antifungal drugs within the anticipated period of 9 weeks. Systemic antifungal therapies were often associated with deleterious effects such as gastro intestinal disorders, allergic reactions and photo-dermatitis, renal and hepatic dysfunctions $[31,32]$.

Mikaili, et al [33] in a study that evaluated the efficacy of immunization with a live $T$. verrucosum vaccine against bovine ringworm concluded that the vaccine could produce protective immunity against dermatophytosis in vaccinated cattle. Meanwhile, Arslan, et 
al [34] did not observe any adverse effect on the liver and kidney functions when he treated nine dermatophytosis affected cows with attenuated strain of $T$. verrucosum. Consequently, several authors [34-36] have considered $T$. verrucosum vaccine a better option for the treatment of cattle ringworm than other antifungal agents in time and efficiency.

The literature is replete with reports of the occurrence of ringworm in humans associated with animal contact in our country $[4,10,11]$. Ameh and Okolo [37] in a study of dermatophytosis among school children observed that, of the two hundred and fifty-six pupils diagnosed of dermatophytosis, $26.25 \%$ were due to $T$. verrucosum infection, second only to T. mentagrophytes (29.75\%). However, there have not been much coordinated attempts at studying the disease among animals in Nigeria. It is recommended that concerted efforts should be made at determining the prevalence of ringworm among the cattle population in the country and all dermatophytes involved should be isolated and characterized so that the most prevalent species can be used to produce vaccine for the protection of livestock against the disease as practiced in Norway and some other parts of the world.

\section{Acknowledgement}

We thank the Executive Director, National Veterinary Research Institute, Vom, Nigeria for permission to publish this work.

\section{Conflicts of Interest: None declared.}

\section{References}

[1] Weitzman I. \& Summerbell R.C. (1995) Clinical Microbiology Review, 8,240-259.

[2] Girgis S.A., Fakkar M.N.Z., Badr H., Shaker O.A., Metwally F.E. \& Bassim H.H. (2006) Egyptian Dermatology Online Journal, 2 (2), 1-23.

[3] Wabacha J.K., Gitau G.K., Bebora L.C., Bwanga C.O., Wamuri Z.M. \& Mbithi P.M. (1998) Journal of South African Veterinary Association, 69(4), 172-173.

[4] Nweze E.I. (2010) Revista Iberoamericana de Micologia, 27(4), 191-194.

[5] Swai E.S. \& Sanka P.N. (2012) Veterinary World, 5(5), 297-300.

[6] Papini R., Nardoni S., Fanelli A. \& Manciani F. (2009) Zoonoses Public Health, 56(2), 59-64.

[7] AL-Ani F.K., Younes F.A. \& AL-Rawashdeh F.O. (2002) Acta Veterinaria Brno, 71, 55-60.

[8] Cam Y., Gümüssoy K.S., Kibar M., Apaydin N. \& Atalay Ö. (2007) Veterinary Record, 160, 408-410.

[9] Acha P.N. \& Szyfres B. (2003) Zoonoses and communicable diseases common to man and animals. Volume 1. Bacterioses and mycoses, 3rd ed., Pan American Health Organization (PAHO), Scientific and Technical Publication No. 580. Dermatophytosis, Washington DC, 332-339.

[10]Makinde A.A., Lombin L.H., Chuku A., Ta'ama L., Dalis J.S., Shaibu S.J. \& Irokanulo E.A. (2010) Journal of Applied Science and environmental Management, 14(4), 97-10.

[11]Ndako J.A., Osemwegie O.O., Spencer T.H., Olopade B.K., Yunusa G.A. \& Banda J. (2012) Global Advanced Research Journal of Medicine and Medical Sciences, 1(3), 49-56.

[12]Adekeye J., Ado P., Kwanashie C.N., Adeyanju J. \& Addullahi
S. (1989) Zaria Veterinarian, 4(1), 84-86.

[13]Koneman E.W. (1997) Color Atlas and Textbook of Diagnostic Microbiology, 5th ed., J.B. Lippincott Company, Philadelphia, PA.

[14]Radostits O.M., Blood D.C., Gay C.C. (1994) Veterinary Medicine: A textbook of the diseases of cattle, sheep, pigs, goats \& horses, 8th ed., Baillière Tindall, London.

[15]Yuksel T. \& Likit M. (2012) Medical Mycology, 50(4), 346-352.

[16]Rosen T. (1997) Consultant, 37, 1545-1557.

[17]Forbes B.A., Sahm D.F. \& Weissfeld A.S. (2002) Laboratory Methods in Basic Mycology, Diagnostic Microbiology 11th ed., Mosby Inc, 11830 west line Industrial Drive St. Louis, Missouri 63146, USA.

[18]Robert R. \& Pihet M. (2008) Mycopathologia, 166, 295-306.

[19]Panasiti V., Borroni R.G., Devirgiliis V., Rossi M., Fabbrizio L., Masciangelo R., Bottoni U. \& Calvieri S. (2006) Mycoses, 49, 26 -29 .

[20]Shams-Gahfarokhi M., Mosleh T.F., Ranjbar B.S. \& Razzaghi A.M. (2009) Iranian Journal of Microbiology, 1(3), 31-36.

[21]Kane J. \& Smitka C. (1978) Journal of Clinical Microbiology, 8 (6), 740-747.

[22]Weitzman I., Salkin F.I., Rosenthal S.A. (1983) Journal of Clinical Microbiology, 18(1), 203-205.

[23]Kwanashie C.N., Ado P.B. \& Saidu S.N.A. (1989) Tropical Veterinarian, 7, 42-44.

[24]Akbarmehr J. (2011) African Journal of Microbiology Research, 5(11), 1268-1271.

[25]Ming P.X., Ti Y.L. \& Bulmer G.S. (2006) Mycopathologia, 161, 225-228.

[26]Maslem M.M. (2000) Journal of Dermatology, 42, 1-4.

[27]Wisal G.A. \& Salim M.O. (2010) Sudan Journal of Veterinary Research, 25, 49-53.

[28]Eljack H., Abdo E.M.A., Shuaib Y.A. \& Elham A.S. (2011) University of Khartoum Journal of Veterinary Medicine and Animal Production, 2(2), 131-141.

[29]Umunna A.M., Ibe O.R. \& Ada N.U.O. (2013) Journal of Veterinary Medicine and Animal Health, 5(5), 124-128.

[30]Oskanlar Y., Aktas M.S. \& Kirecci E. (2009) Kafkas Üniversitesi Veteriner Fakültesi Dergisi, 15(1), 141-144.

[31]Chien R.N., Yang L.J., Lin P.Y. \& Liaw Y.F. (1977) Hepatology, 25(1), 103-107.

[32]Kim T.H., Kim B.H., Kim Y.W., Yang D.M., Han Y.S., Dong S.H., Kim H.J, Chang Y.W., Lee J.I. \& Chang G.R. (2003) Journal of Gastroenterology and Hepatology, 8, 1426-1429.

[33]Mikaili A., Chalabi M., Ghashghaie A., Mostafaie A. (2012) African Journal of Microbiology Research, 6(23), 4950-4953.

[34]Arslan H.H., Yarim G.E., Yavuz O. \& Bas B. (2007) Revue de Médecine Vétérinaire, 158(10), 509-513.

[35]Gudding R. \& Lund A. (1995) Canadian Veterinary Journal, 36, 302-306.

[36]Zahran R.N. \& Abdeen E.A. (2013) American Journal of Immunology, 9(4), 139-147.

[37]Ameh I.G. \& Okolo R.U. (2004) Pakistan Journal of Biological Sciences, 7(7), 1109-1112. 